\title{
DISTRIBUIÇÃO ESPACIAL DO CARANGUEJO OCYPODE QUADRATA (FABRICIUS, 1787) (CRUSTACEA, OCYPODIDAE), NA PRAIA DO FORNO (ARRAIAL DO CABO, RJ)
}

\section{ARTIGO ORIGINAL}

MATOS, Thiago da Silva ${ }^{1}$

SILVA, Turíbio Tinoco da ${ }^{2}$

GOMES, Flávio Antônio da Costa ${ }^{3}$

NALINI, Gabriela ${ }^{4}$

MATOS, Thiago da Silva. Et al. Distribuição espacial do caranguejo Ocypode Quadrata (Fabricius, 1787) (Crustacea, Ocypodidae), na Praia do Forno (Arraial do Cabo, RJ). Revista Científica Multidisciplinar Núcleo do Conhecimento. Ano 04, Ed. 08, Vol. 07, pp. 104-115. Agosto de 2019. ISSN: 2448-0959, Link de acesso: https://www.nucleodoconhecimento.com.br/biologia/caranguejo

\section{RESUMO}

O presente estudo levantou a distribuição espacial do caranguejo Ocypode quadrata de acordo com a quantidade e diâmetro das tocas encontradas, na Praia do Forno ( $22^{\circ} 58^{\prime} \mathrm{S}, 42^{\circ} 00^{\prime} \mathrm{O}$ ), praia arenosa localizada no município de Arraial do Cabo-RJ. As amostragens foram realizadas nos dias 01/05, 07/08 e 08/08/2015. Foram distribuídos aleatoriamente 10 transectos perpendiculares a linha d'água que se constituíam de três retângulos de $2 \mathrm{~m} \times 5 \mathrm{~m}$, espaçados entre si por 2 metros, com uma distância de

1 Mestre em Biotecnologia Marinha, pós-graduação em Biologia Marinha e Oceanogradia, graduação em Ciências Biológicas.

${ }^{2}$ Mestre em Geociências pela Universidade Federal Fluminense (UFF).

${ }^{3}$ Mestre em Bioincrustação pela Universidade Estadual do Rio de Janeiro (UENF).

${ }^{4}$ Mestre em Dinâmica dos Oceanos e da Terra (UFF). 
50 metros do próximo transecto. A divisão em três retângulos teve como objetivo amostrar as três áreas de interesse do estudo, médio litoral (ML), supra litoral (SL) e vegetação (VG), determinadas a partir da influência da variação da maré sobre o ambiente praial. Foram contadas todas as tocas com marcas e evidências de presença do caranguejo em cada transecto e os diâmetros foram medidos $(\mathrm{mm})$, com o auxílio de paquímetro. A área do SL apresentou maior quantidade média de tocas em relação ao $M L$ e a $V G$, não sendo encontrada diferença significativa entre o $M L$ e a VG. Na distribuição de tocas por diâmetro médio foi encontrada diferença significativa entre todos os ambientes, sendo as tocas encontradas na VG as de maior diâmetro, seguidas pelas tocas do SL, e posteriormente o $\mathrm{ML}$ com o menor diâmetro, devido possivelmente a sensível desidratação de indivíduos de menor porte de O.quadrata. $O$ trabalho constatou que os indivíduos maiores procuram a vegetação para construir suas tocas, por possuírem melhor mobilidade e independência do meio aquático mais próximo do que indivíduos menores, tendo capacidade de escavar tocas profundas. Além disso, a subdivisão em três ambientes (ML, SL, VG), permitiu a visualização da influência da variação da maré na determinação do padrão de distribuição espacial em relação ao diâmetro das tocas.

Palavras-chave: Ocypode quadrata, Praia arenosa, Diâmetro de tocas, Praia do Forno, Arraial do Cabo.

\section{INTRODUÇÃO}

As praias arenosas são caracterizadas por serem ambientes diversificados e dinâmicos. São regidas principalmente por fatores físicos como marés, ondas, correntes e ventos, os quais determinam o padrão hidrodinâmico e a deposição sedimentar nestes ecossistemas (BROWN; MCLACHLAN,1990). Embora as praias arenosas sejam caracterizadas como regiões pobres biologicamente, sua fauna é altamente adaptada a variações ambientais, como por exemplo, na região entre marés, sendo composta principalmente por invertebrados pertencentes tanto a infauna quanto a epifauna (VELOSO et al., 1997; BLANKENSTEYN, 2006). 
Dentre os organismos da epifauna, destaca-se o caranguejo Ocypode quadrata (Crustacea: Decapoda), conhecido popularmente como "maria-farinha", que possui ampla distribuição geográfica, com ocorrência registrada desde o litoral sul do Brasil até a América do Norte (MELO,1996). Possui um corpo de formato quadrado, podendo atingir $8 \mathrm{~cm}$, com coloração amarelada semelhante a areia da praia (TEIXEIRA et al., 2008).

O Ocypode quadrata utiliza as regiões do médio litoral, do supra litoral e da vegetação de restinga, para a construção de suas tocas. Enquanto os indivíduos jovens estabelecem suas tocas na região de médio litoral com alguns registros em regiões do supra litoral, os adultos ocupam predominantemente o supra litoral (TURRA et al., 2005). Acredita-se, que isto ocorra porque os indivíduos pequenos se restringem a áreas mais úmidas, uma vez que possuem menor resistência à hidratação e menor habilidade para escavar tocas profundas.

A utilização e construção destas tocas se fazem por diversos motivos, dentre eles a competição por recursos alimentares. A competição é caracterizada como uma interação de disputa entre indivíduos, que ocorre devido a demandas similares por recursos limitados. Essa interação pode resultar na redução da sobrevivência, crescimento e/ou reprodução de ao menos um dos indivíduos envolvidos (BEGON, 2006), sendo a toca uma proteção contra predadores.

As tocas também servem como recurso ao $O$. quadrata, frente a condições ambientais estressantes. Dentre estas condições se enquadram variações na intensidade dos ventos, na temperatura, e na altura de ondas e marés. Uma vez que é uma espécie sensível a estas alterações ambientais, como estratégia de sobrevivência $0 O$ .quadrata realiza o seu recrutamento no interior das tocas (ALBERTO; FONTOURA, 1999), garantindo a continuidade da espécie.

Praias que sofrem influência de antropização podem se tornar ambientes estressantes para o O.quadrata, através, por exemplo, da supressão de habitat, deposição de resíduos sólidos e tráfego de veículos (WOLCOTT; WOLCOTT, 1984; Turra et al., 2005; BLANKENSTEYN, 2006; SCHLACHER et al., 2007). Com isso, segundo 
(WOLCOTT, 1978), o hábito de se abrigarem em tocas é um importante fator de sobrevivência em praias com intensa influência antrópica.

Diversos autores têm demonstrado a utilidade dos caranguejos do gênero Ocypode como indicador biológico de impacto ambiental e sua viabilidade para estudos de monitoramento em curto prazo (BARROS, 2001; BLANKENSTEYN, 2006; NEVES; BENVENUTI, 2006). Além disto, ecologicamente, o O. quadrata desempenha um papel importante na transferência de energia entre diferentes níveis tróficos dos ecossistemas costeiros, além de consumir detritos orgânicos presentes no ambiente, contribuindo com a limpeza e manutenção da qualidade ambiental (PHILIPS, 1940).

A Praia do Forno é caracterizada como uma praia arenosa que pertence a Reserva Extrativista Marinha de Arraial do Cabo. Recebe influência direta da variação da maré, sendo um ambiente propício à ocorrência do $O$. quadrata.

Uma vez que desempenha papel importante na cadeia trófica, alterações na abundância e distribuição de $O$. quadrata podem refletir em modificações nos níveis tróficos superiores. Com isso, estudos sobre o seu comportamento podem servir de subsídio para melhor gestão e manejo deste recurso marinho. Diversos estudos abordam a distribuição espacial do O.quadrata (ALBERTO; FONTOURA, 1999), (ARAÚJO et al, 2008), (PEREZ; VIANNA, 2007), entre outros. No entanto, devido à ausência de estudos na região de Arraial do Cabo sobre o caranguejo maria-farinha, o objetivo deste trabalho é quantificar a distribuição espacial de tocas do O.quadrata na Praia do Forno em Arraial do Cabo-RJ, testando a hipótese da existência de diferença na distribuição do caranguejo em três ambientes diferentes da praia, quanto ao diâmetro médio da toca, a fim de contribuir para uma melhor compreensão da ocorrência desta espécie na região, sendo este trabalho um estímulo a necessidade da investigação e produção de outros estudos sobre este animal na região. 


\section{MATERIAIS E MÉTODOS}

\section{1 ÁREA DE ESTUDO}

Arraial do Cabo possui uma área total de 160,286 km², sendo que, apenas $85 \mathrm{~km}^{2}$ são terrestres. Suas coordenadas geográficas são $\left(22^{\circ} 57^{\prime} \mathrm{S}\right.$ a $22^{\circ} 59^{\prime} \mathrm{S} ; 42^{\circ} 00^{\prime} \mathrm{O}$ a $42^{\circ}$ 02'O). Limita-se ao Norte com o Município de Cabo Frio e a Lagoa de Araruama, ao Sul e ao Leste com o Oceano Atlântico e ao Oeste com a Lagoa de Araruama. A altitude média da região é de aproximadamente 2,0 metros acima do nível do mar (IBGE/CIDADES, 2010). O clima de Arraial do Cabo é caracterizado como semi-árido, com chuvas concentradas no verão e estiagens nos meses de abril a outubro, sendo a temperatura média no verão de $25,3^{\circ} \mathrm{C}$ e no inverno, 20,6드 (Duarte, 1998).

O município possui $30 \mathrm{~km}$ de praias, todas de alto valor turísticos, sendo as principais: Praia dos Anjos (onde se localiza o Porto do Forno), Praia do Forno, Praia Grande, Prainha, As Prainhas da Atalaia, Praia da llha do Farol, Praia Grande, Praia do Monte Alto, entre outras. Ao longo das últimas décadas, a cidade de Arraial do Cabo vem sofrendo a ocupação desordenada, com a especulação imobiliária sem controle e alta densidade de turistas. Durante os meses de temporada (janeiro, fevereiro, março e abril) ocorre um extremo fluxo de pessoas para Arraial do Cabo, o que provoca a superlotação das praias da cidade, pois a areia nestes períodos em determinadas praias fica superlotada, com maior concentração de pessoas justamente nas regiões de supra litoral, médio litoral e na faixa de vegetação, áreas onde são registradas a ocorrência do caranguejo maria - farinha.

A área de estudo deste trabalho foi a Praia do Forno $\left(22^{\circ} 58^{\prime} \mathrm{S}, 42^{\circ} 00^{\prime} \mathrm{O}\right)$, a qual possui extensão em torno de 600 metros de areia (Figura 1). A variação da maré neste ambiente foi de 2,21m no dia 01/05, 07/08 de 2,69m e 2,49m no dia 08/08/2015, de acordo com dados provenientes do marégrafo do INSTITUTO DE ESTUDOS DO MAR ALMIRANTE PAULO MOREIRA (IEAPM)/MARINHA DO BRASIL, coordenado pelo Doutor Rogério Candella , localizado no Porto do Forno. A Praia do Forno é uma área com grande impacto antropogênico, recebendo no verão e dias de feriado, uma grande quantidade de turistas e banhistas. 
Figura 1. Localização da cidade de Arraial do Cabo, acentuando a Praia do Forno, com suas coordenadas geográficas.

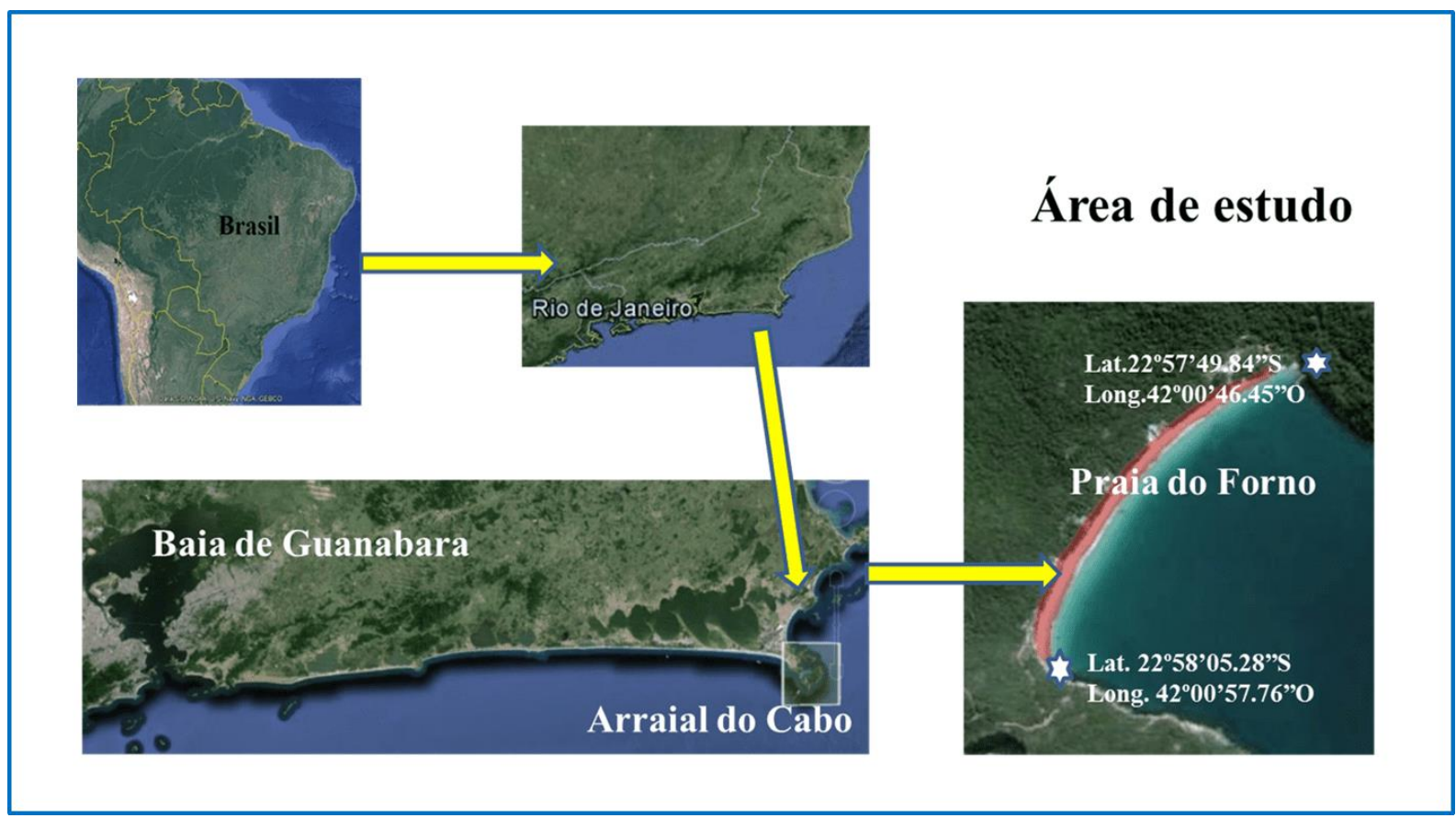

Fonte: Adaptado do Google Earth (2015).

\subsection{DELINEAMENTO AMOSTRAL}

As amostragens foram realizadas nos dias (01/05; 07/08; e 08/08/2015), no período diurno, às $07 \mathrm{~h} 30 \mathrm{~min}$. Com o intuito de avaliar a distribuição espacial das tocas e seu diâmetro foram distribuídos aleatoriamente 10 transectos perpendiculares a linha d'água. Os transectos constituíam três retângulos de $2 \mathrm{~m} \times 5 \mathrm{~m}$, espaçados entre si por 2 metros, com uma distância de 50 metros do próximo transecto. A divisão em três retângulos teve por objetivo amostrar as três áreas de interesse de estudo, médio litoral, supra litoral e vegetação, respectivamente. Foram contadas todas as tocas com marcas e evidências da presença do caranguejo em cada transecto. As tocas encontradas foram medidas com paquímetro de precisão de $0,1 \mathrm{~mm}$ (Figura 2).

Figura 2. Esquema ilustrativo do método de amostragem. A metodologia foi composta por um total de dez transectos perpendicular a linha da costa, e em cada transecto, 
três retângulos de $10 \mathrm{~m} 2$, sendo distribuído um retângulo em cada ambiente da faixa litorânea.

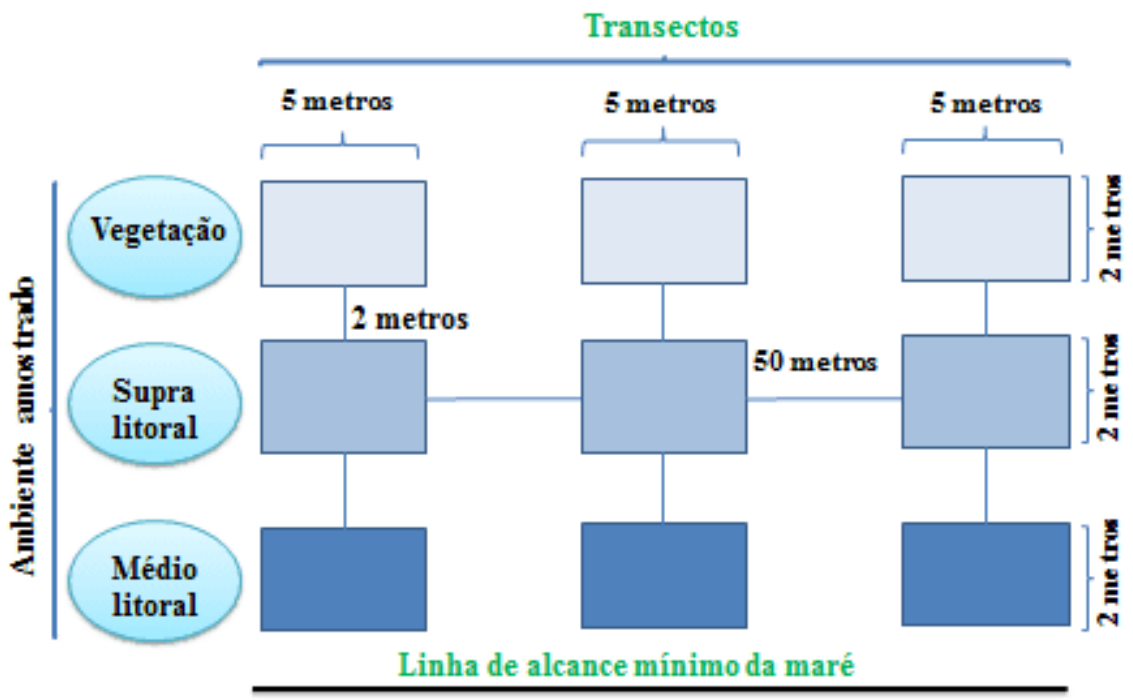

Fonte: Autor.

\subsection{ANÁLISE DOS DADOS}

A análise dos dados e o delineamento amostral foram baseados e adaptados do trabalho de Araujo et al. (2008). O delineamento era composto por três tratamentos: médio litoral $(\mathrm{ML})$, supra litoral $(\mathrm{SL})$, e vegetação $(\mathrm{VG})$. As variáveis dependentes: quantidade e diâmetro das tocas foram analisados e relacionados com os diferentes tratamentos. Para cada uma destas variáveis foi realizada uma análise de variância de uma via (ANOVA). Os pressupostos exigidos para a execução da ANOVA, normalidade dos dados e a homogeneidade das variâncias, foram testados através dos testes de Shapiro-Wilk e de Bartlett, respectivamente. Os dados de quantidade das tocas não possuíam distribuição normal, com isso foram transformados através de função logarítmica a fim de atingir a normalidade destes dados. As médias das variáveis que atingiram probabilidade de significância $<0,05$ foram comparadas pelo teste Post-Hoc de Tukey (HSD). Os dados da variável dependente diâmetro das tocas 
possuíam distribuição normal para análise. Todos os dados obtidos foram analisados com o auxílio do software livre Rstudio 0.95 .263 , e os gráficos foram gerados com o software Excel 2010 e Power Point 2010.

\section{RESULTADOS E DISCUSSÃO}

A área total de $6.000 \mathrm{~m} 2$ foi amostrada, contabilizando uma densidade de tocas 0,09 tocas/m2. O total de tocas encontradas foi de $596: 74$ no ML, 425 no SL e 97 na VG. A quantidade de tocas diferiu significativamente entre os ambientes ML e SL, e VG e $S L$, não sendo encontrado diferença significativa entre o ML e o VG (Figura 3; Quadro1).

Figura 3. Valores da quantidade de tocas de Ocypode quadrata nos tratamentos médio litoral, supra litoral, e vegetação. Letras diferentes entre si indicam diferença significativa $(p<0,001)$ entre tratamentos. Letras iguais indicam ausência de diferença significativa entre tratamentos. Barras verticais representam desvio padrão da média. Asterisco $\left.{ }^{* \star *}\right)$ indica que há diferença estatística de variância entre os tratamentos é a nível de significância de $p$ valor $<0,001$.

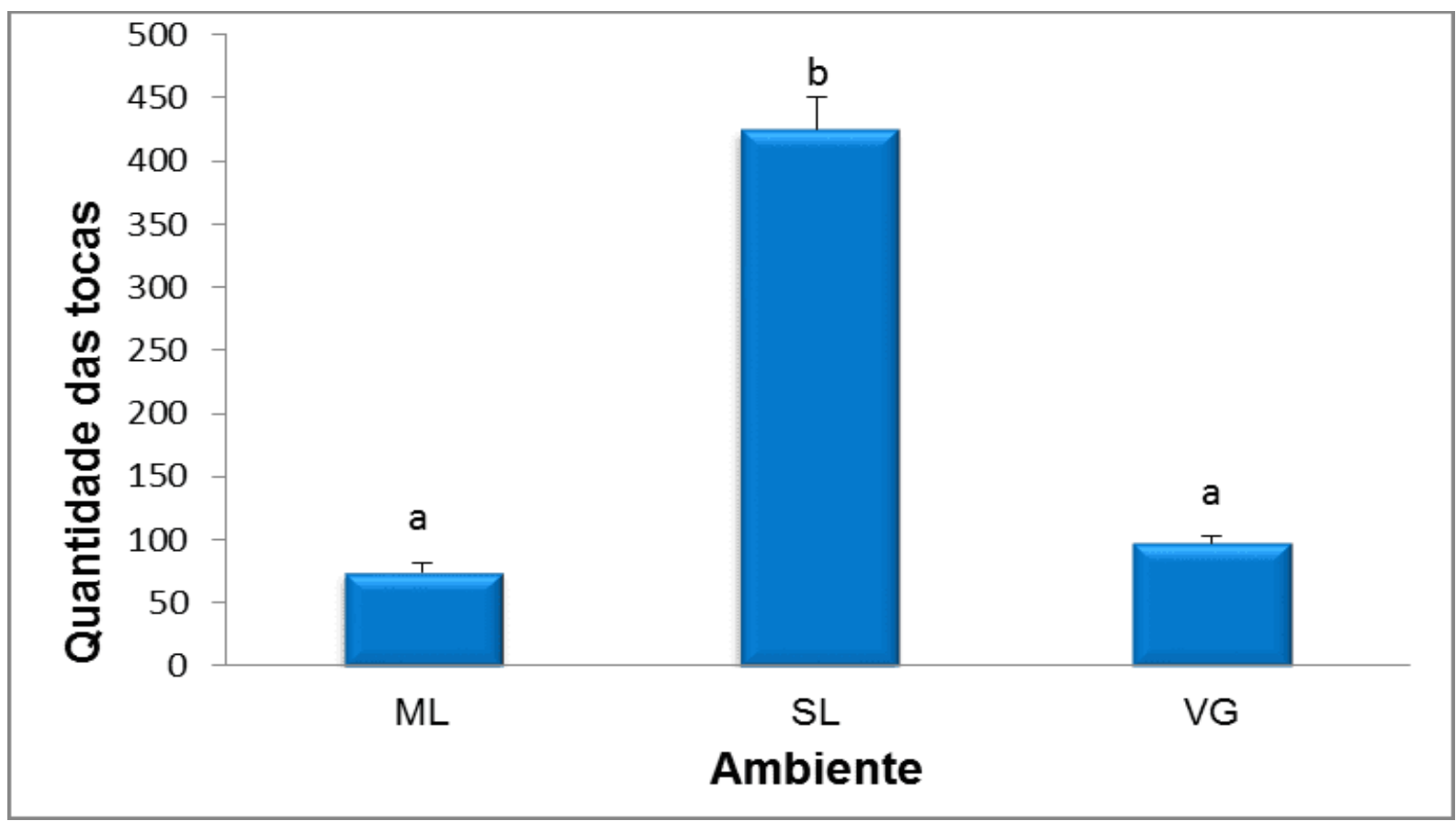

Fonte: Autor. 
Quadro 1. Tabela da análise de variância (ANOVA) dos valores de distribuição das tocas de Ocypode quadrata, entre os tratamentos: médio litoral, supra litoral, e vegetação. Onde $\mathrm{GL}=$ grau de liberdade; Soma $\mathrm{SQ}=$ soma dos quadrados; Média $\mathrm{SQ}=$ quadrado médio; Valor de $F=$ distribuição $F ; p$ valor= probabilidade de significância. Asterisco $\left.{ }^{(* \star}\right)$ indica que há diferença estatística é em nível de significância de $\mathrm{P}$ valor $<0,001$.

\begin{tabular}{|l|l|l|l|l|l|}
\hline Fonte & GL & Soma SQ & Média SQ & F & P valor \\
\hline Tratamentos & 2 & 5.4038 & 2.70188 & 51.801 & 0.0001641 \\
\hline Resíduos & 6 & 0.3130 & 0.05216 & & \\
\hline
\end{tabular}

Fonte: Autor.

O presente estudo teve por proposta a hipótese de diferenciação da distribuição deste caranguejo nas três áreas da praia, como, médio litoral, supra litoral e vegetação, e essa hipótese foi confirmada apenas no supra litoral, com diferença significativa neste ambiente. Trabalhos anteriores tiveram resultados semelhantes, com a densidade de tocas maior na região próxima ao supra litoral (Turra et al. 2005). Segundo (Barras 1963) a entrada de água nas tocas devido à ação da maré destrói o abrigo. Acreditase que mesmo os indivíduos maiores se dispersarem mais distante da linha de maré, chegando a vegetação, uma grande quantidade prefere ficar no supra litoral, distante da linha d'água, porém não tão distante quanto a vegetação, pois mantendo ainda um recurso hídrico ao escavar suas tocas.

Esse padrão de distribuição pode ter influências diretas de algumas variáveis, segundo MAIA (2012), como horário e tábua das marés, nível de umidade, presença de chuvas antes e durante as coletas, granulometria da areia do ambiente estudado, entre outros fatores trópicos e antrópicos, sugerindo futuros estudos sobre as respectivas variáveis.

O diâmetro médio das tocas diferenciou significativamente entre os ambientes. Os maiores valores foram encontrados na vegetação $3,9 \pm, 01 \mathrm{~cm}$ (média \pm desvio padrão), 
o menor valor no médio litoral $(1,4 \pm 0,4 \mathrm{~cm})$, e no supra litoral $2,59 \pm 0,94 \mathrm{~cm}$ (Figura 4; Quadro 2).

Figura 4. Valores de diâmetro médio das tocas nos tratamentos médio litoral, supra litoral e vegetação. Letras diferentes entre si indicam diferença significativa $(p<0,001)$ entre tratamentos. Letras iguais indicam ausência de diferença significativa entre tratamentos. Barras verticais representam desvio padrão da média. Asterisco $\left(^{* \star *}\right)$ indica que há diferença estatística de variância entre os tratamentos é a nível de significância de $p$ valor $<0,001$.

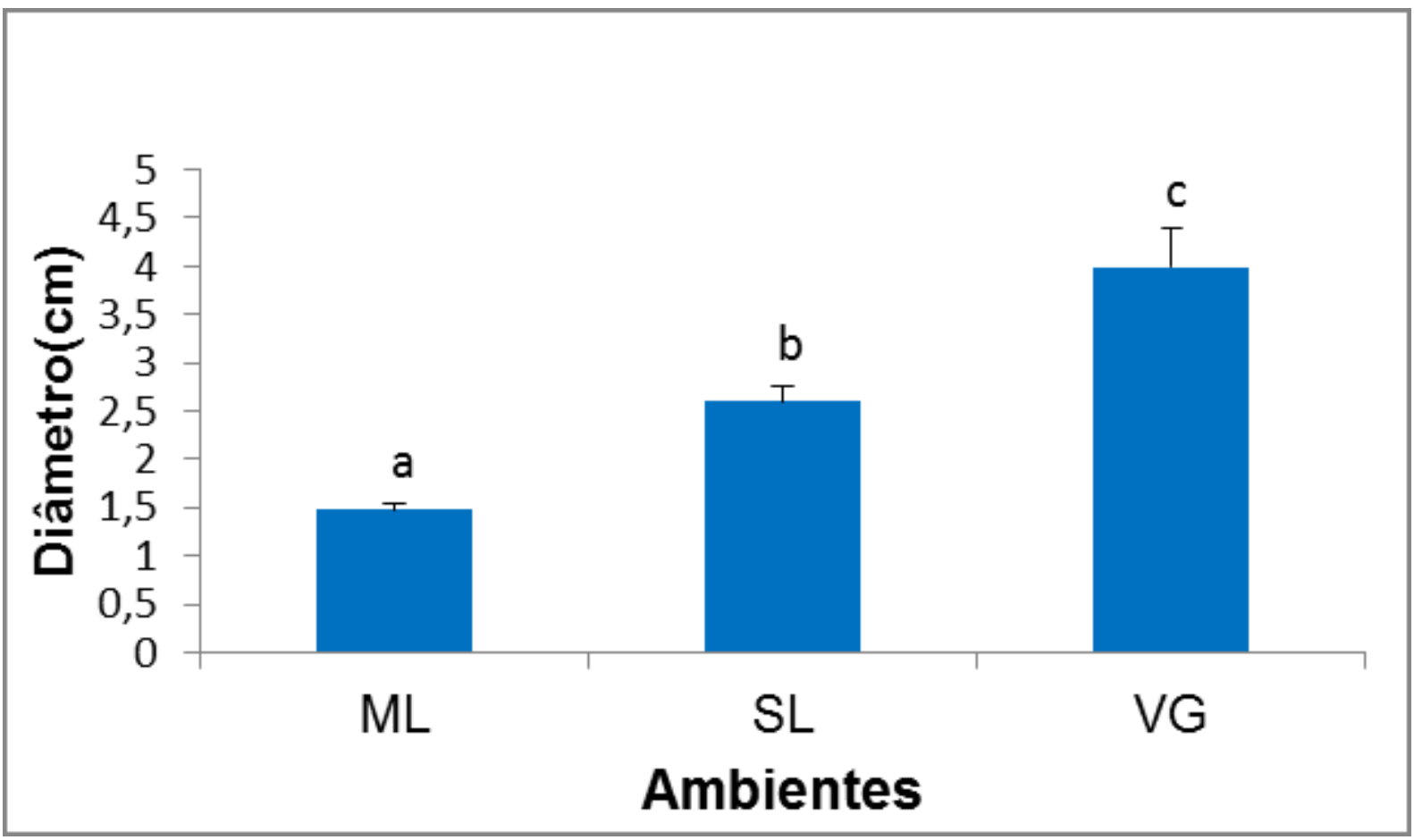

Fonte: Autor.

Tabela 2. Tabela da análise de variância (ANOVA) dos valores de diâmetro das tocas de Ocypode quadrata, entre os tratamentos: médio litoral, supra litoral, e vegetação. Onde $\mathrm{GL}=$ grau de liberdade; Soma $\mathrm{SQ}=$ soma dos quadrados; Média $\mathrm{SQ}=$ quadrado médio; Valor de F= distribuição F; $\mathrm{p}$ valor= probabilidade de significância. Asterisco $\left.{ }^{(* \star}\right)$ indica que há diferença estatística é em nível de significância de $\mathrm{P}$ valor $<0,001$.

\section{Fonte}

GL Soma SQ Média SQ $\mathrm{F}$

$P$ valor 


\begin{tabular}{|l|l|l|l|l|l|}
\hline Tratamentos & 2 & 8.8217 & 4.4108 & 70.699 & $6.745-05$ \\
\hline Resíduos & 6 & 0.3743 & 0.0624 & & \\
\hline
\end{tabular}

Fonte: Autor.

Acredita-se, que isto ocorra porque os indivíduos pequenos se restringem a áreas mais úmidas, uma vez que possuem menor resistência à hidratação e menor habilidade para escavar tocas profundas. De acordo com (TURRA et al., 2005), estes animais possuem distribuição espacial de acordo com seu tamanho, e esse padrão foi encontrado por este estudo na Praia do Forno, comprovando a hipótese de diferença nos ambientes segundo o diâmetro das tocas, alguns trabalhos como o de (Araújo et al., 2008) também foi encontrado esse padrão de distribuição.

Supostamente, ou outra via de explicação para o diâmetro médio, é que Neves e Benvenuti (2006) encontraram menor quantidade de tocas de O. quadrata, em praias com maior interferência humana no Rio Grande do Sul, onde, o fluxo de veículos e pedestres é intenso durante o ano, condição semelhante a encontrada na Praia do Forno em Arraial do Cabo, onde também é possível observar a presença de 8 cachorros morando na praia, deixando na areia marcas de suas patas, sinais de modificação do ambiente arenoso, habitat do caranguejo O. quadrata.

A constante utilização do ambiente arenoso por meio dos pedestres, banhistas, esportistas, e tráfego de veículos (caiaques), potencializam a redução da densidade populacional de O.quadrata, ou até mesmo sua migração obrigatória para outras áreas do ambiente arenoso não disponível ainda para sua fase de maturação, como a ocorrência de organismos mais jovens na vegetação, pois segundo (TURRA et al., 2005).

Mesmo sendo justificados a presença de organismos maiores próximos da vegetação, devido sua habilidade de escavar tocas profundas, e os menores mais próximos a linha de maré, devido sua dependência de hidratação das brânquias, foi possível observar também alguns organismos menores próximo a vegetação, sendo este 
comportamento uma possível fuga de predadores ou estresses submetidos próximo a linha de maré, devendo ser observado e estudado com maior precisão futuramente.

\section{CONCLUSÃO}

A realização deste trabalho possibilitou chegar à seguinte conclusão, que na Praia do forno a distribuição de tocas deste caranguejo quanto a quantidade se da de forma diferente apenas em um dos principais ambientes da faixa arenosa, uma maior quantidade no supra litoral, acredita-se ser devido um ambiente intermediário, possibilitando se abrigar distante do alcance de variação da maré e trafego em geral, e mantendo não muito distante da linha d'água e próximo ao abrigo da vegetação. Assim como também a sua distribuição pelo diâmetro, diferenciaram nos três ambientes amostrados, tendo organismos com maior diâmetro na vegetação, e no Supra Litoral, a presença dos organismos maiores mais próximos da vegetação devidos sua capacidade de escavar as tocas, com este fator, podemos concluir também que os caranguejos de menor diâmetro foram encontrados mais próximos à linha de maré, ressaltando sua dependência do meio úmido, e sua incapacidade de escavar tocas. Este trabalho sugere a possibilidade da realização de outros estudos, que investiguem a influência de uma população de cachorros encontrada vivendo nesta praia, possibilitando a preservação deste animal, e consequentemente, a conservação da biodiversidade, bem como incentivando futuras pesquisas deste organismo, ressaltando sempre a importância destes para o ambiente.

\section{REFERÊNCIAS}

ALBERTO, R.M.F.; M.F. FONTOURA. Age structure spatial distribution of Ocypode quadrata (Fabricius, 1787) on a sandy beach from the South Coast of Brazil (Crustacea, Decapoda, Ocypodidae). Revista Brasileira de Biologia, 59:95108. 1999.

ARAÚJO , C.C.V.; ROSA, D. M.; FERNANDES, J. M. Densidade e distribuição espacial do caranguejo Ocypode quadrata (Fabricius,1787)(Crustacea, 
Ocypodidae) em três praias arenosas do Espírito Santo, Brasil. Biotemas, 21(4): 73-80, ISSN0103 - 1643. dezembro de 2008.

BARRAS R. The burrows of Ocypode ceratophthalmus (Pallas) (Crustácea, Ocypodidae) on a Tidal Wave Beach at Inhaca Island, Moçambique. The Journal of Animal Ecology 32: 73-85. 1963.

BARROS, F. Ghost crabs as tools for rapid assessment of human impacts on exposed sandy beaches. Biological Conservation, 97: 399-404. 2001.

BEGON, M.; C.R. TOWNSEND \& J.L. HARPER. Ecology: from individuals to ecosystems. Blackwell Publishing, Oxford. 2006.

BLANKENSTEYN, A. O uso do caranguejo maria-farinha Ocypode quadrata (Fabricius) (Crustacea, Ocypodidae) como indicador de impactos antropogênicos em praias arenosas da Ilha de Santa Catarina, Santa Catarina, Brasil. Revista Brasileira de Zoologia, 23 (3): 870-876. 2006.

BROWN, A. C.; MCLACHLAN, A. Ecology of sandy beaches. Elsevier Science Publishers, Amsterdam, The Netherlands, 328pp. 1990.

DUARTE, A.C. Condições morfoclimáticas e vegetação do ambiente estépico da região de Cabo Frio, RJ, Brasil. Avaliação atual para uma perspectiva de preservação. Dissertação de Mestrado, Pós-graduação em Geociências, Universidade Federal Fluminense. Niterói, RJ. (1998).

MAIA, Kate - Caranguejos maria-farinha Ocypode quadrata (Crustacea: Brachyura)

constroem suas tocas preferencialmente em substratos com cobertura vegetal? , Curso de Pós-Graduação em Ecologia - Universidade de São Paulo, Revista Biologia da Mata Atlântica, 2012.

MELO, G.A.S. Manual de identificação dos Brachyura (caranguejos e siris) do litoral brasileiro. Plêiade, São Paulo. 1996. 
NEVES, F. M.; BENVENUTI, E. C. The ghost crab Ocypode quadrata (Fabricius, 1787) as a potential indicator of anthropic impact along the Rio Grande do Sul coast, Brazil. Biological Conservation, 33: 431-435. 2006.

PHILLIPS, A. M. The ghost crabs - adventures investigating the life of a curious and interesting creature that lives on our doorstep, the only large crustacean of our North Atlantic coast that passes a good part of his life on land. Natural History, 43: 36-41. 1940.

SCHLACHER, T. A.; THOMPSON, L.; PRICE, S. Vehicles versus conservation of invertebrates on sandy beaches: mortalities in_ icted by off-road vehicles on ghost crabs. Marine Ecology, 28: 354-367. 2007.

TEXEIRA M. F.; TORRES S. F.; CAPITOLI R. R. Principais moluscos e crustáceos decápodos da Praia do Cassino, RS - Textos e proposta didática. Cadernos de Ecologia Aquática, v. 3, n. 2, p. 1-18, 2008.

TURRA, A.; GONÇALVES, M. A. O. \& DENADAI, M.R. Spatial distribution of the ghost crab Ocypode quadrata in low-energy tide-dominated sand beaches. Journal of Natural History 39: 2163-2177. 2005.

VELOSO, V. G.; CARDOSO, R. S.; FONSECA, D. B.. Adaptações e biologia da macrofauna de praias arenosas expostas com ênfase nas espécies da região entre-marés do litoral_fluminense. O ecologia brasiliensis, 3: 121-133. 1997

WOLCOTT, T. G., Ecological role of ghost crabs, Ocypode quadrata (Fabricius) on an ocean beach: scavengers or predators? J. Exp. Mar. Biol. Ecol., Amsterdam, 31: 67-82. 1978.

WOLCOTT, T. G.; WOLCOTT, D. L. Impact of offroad vehicles on macroinvertebrates of a Mid-Atlantic beach. Biological Conservation, 29: 217-240. 1984.

Enviado: Outubro, 2018. 
Aprovado: Agosto, 2019. 